\title{
Teaching experimental film: On the practical and analytic treatment of avant-garde cinema ${ }^{1}$
}

\author{
Volker Pantenburg* - Free University of Berlin, Germany \\ Stefanie Schlüter - Arsenal Institute for Film and Video Art, Germany \\ First published in Pantenburg and Schlüter (2011) \\ Translated from the German by Flora Schiele
}

\begin{abstract}
This article highlights the potential of experimental and avant-garde cinema in film educational contexts. In the first part, Stefanie Schlüter evaluates her practical experience in working with 10- to 11-year-old schoolchildren. Based on reflections by Peter Kubelka, Stan Brakhage and others, she emphasizes the act of engaging with film material (scratching, painting) as a genuine haptic and perceptual experience. In the second part, Volker Pantenburg reframes classical avant-garde films by Gary Beidler, Peter Tscherkassky and Morgan Fisher as valuable, implicitly didactic 'lessons of cinema'. In a playful and elaborate way, these films perform and display basic qualities of the moving image: movement and stillness, materiality and narration, format and affect.
\end{abstract}

Keywords: experimental cinema; materiality; children's workshops; analogue film; haptic approach

\section{On the practical treatment of avant-garde cinema}

Experimental film plays a subordinate role in film education for children and young people, if it can be said to play a role at all. This could be caused by the marginal value avant-garde and experimental films are assigned, indicated by the fact that these films are almost exclusively distributed by non-commercial distributors: if and to what extent films are brought into education is strongly dependent on the resources of the distributor. ${ }^{2}$ Initiatives for education about avant-garde and experimental film, and also about video art, have their established place in film festivals, galleries and museums. They exist independently of the dominant modes of film education, which concentrate on contemporary narrative or documentary film productions, and which tend to privilege ethical access to the film over aesthetic access. ${ }^{3}$

However, even within aesthetically oriented educational approaches to film, avant-garde and experimental film is barely included in education directed at children and young people, ${ }^{4}$ even though the educative impulse within this tradition is particularly striking. Avant-garde film-makers have always acted on very different levels as mediators of this 'new vision', for which avant-garde cinema has wanted to open the eyes of its viewers from the beginning. Some examples include Hans Richter, Jonas Mekas, Maya Deren, Stan Brakhage, Hollis Frampton and Peter Kubelka, to name a few who have furthered the production of cinematic knowledge, in terms of both theory and practice, not just with their films, but also through texts and talks, or as founding members of distribution cooperatives, archives and film libraries. These 
parallel educational activities go hand in hand with the educational impulses of the films, which - with different aesthetic strategies from narrative cinema - make reference to their cinematic principles, their materials and not least to film perception.

This does not remain without consequences for education. Where the cinematic aspect of the film is signalled as the subject, where the film acts as its own mediator, it is not necessary to take detours starting with narrative content to find a way back to the film. ${ }^{5}$ With avant-garde and experimental film, the danger of the pedagogical separation of content, form and medium can be bypassed, because the films always start with what should be taught: the cinematic aspect of the film.

\section{The kids have always liked it}

Why are children more open to abstract films - films without a narrative, which have no clear referential relationship with reality - than many adults? Even if this question cannot be asked or answered with universal validity, I wish to pursue it by focusing on the obviously different perceptual modes of children and adults. I will approach this question from an artistic perspective and not, as perhaps suggests itself, from a perspective of developmental psychology. To that end, I will first focus on an essay by the writer Wilhelm Genazino (2007), whose discussion of the phenomenon of photography leads to a contemplation of the theory and aesthetics of perception. Genazino's ideas, supplemented by quotations from the film-makers Peter Kubelka and Stan Brakhage, can serve as a blueprint for the modes of reception of avant-garde and experimental film, as all three positions associate an authentic mode of perception with childhood.

In his essay 'Der gedehnte Blick' ['The prolonged gaze'], Genazino (2007) develops an aesthetic position that deals with the eye's relationship to the world. $\mathrm{He}$ questions on the one hand the 'gazes' that we send out into the world from our earliest childhood, and on the other hand the recognition-producing role of images, which as a consequence of our restless 'looking out into the world' - mature within us. Our gaze biography works, according to Genazino (ibid.: 45), like 'a sort of mini-viewer' who accompanies our further looking and determines what we see and understand and how we see and understand it, over the course of our lives. ${ }^{6}$ Genazino's essay emphasizes the particular importance of 'childlike perception', and in doing so goes into the prelinguistic phase, in which a child's visual relationship to the world is particularly strongly pronounced. By focusing on early childhood, Genazino expresses a fundamental scepticism of hermeneutically and linguistically founded cognition models, which assume that the perceiving subject makes progressively more and more links, and that therefore suggest the possibility that their understanding of the world is always becoming more developed:

Every child has an individual visual history, before it begins to connect frequently seen images with thought content. ... In the conflation of looking, thinking and speaking, our understanding of the world is always becoming more perfect. I consider this widely accepted anthropology as insufficient; in short, I believe that at its crucial point it is not authentic enough, because the end result - the world which is accepted into vision and thought because it is understood - appears to me to be too optimistic. My speculation is that from the beginning, children retain a feeling that they do not correctly understand what they see, because that which they see cannot be correctly, adequately, or completely understood. ... We remember our own childhood gazes, and when we remember as accurately as possible, then it must cross our minds that, as a rule, we 
only understood the beginning of something. (Ibid.: 49-50; translated by Stefanie Schlüter)

According to Genazino, we can only ever have fragmentary knowledge of that which we have seen, and it would be impossible to piece together these fragments like a jigsaw to create a whole. Genazino (ibid.) argues that 'through the seeing years of childhood an unusual coexistence of numerous sensory impressions' develops, which we gradually merge together to form units of meaning and 'at some point, when we are mature and are tired of the eternal fragmentary knowledge, we view them as more or less complete images of images, when really we only encountered their shadows'. According to Genazino (ibid.: 50), children consider the 'not-properly-understood as not-properly-understood'. While one should imagine one's perception as an 'endless mishmash of beginnings', 'an accumulation of baffling picture puzzles', from which the 'emotion of an enigmatic perception' (ibid.: 57) derives, adults, when looking, are always eager to synthesize picture puzzles and thereby solve them. The way that adults look at things [meaning art objects] assigns them meanings that cannot come purely from the things themselves (ibid.: 54). They even manage 'to construct adventurous meanings for images, without ever having learnt anything about the hermeneutical problems which jumping around so freely brings with it' (ibid.: 56). Genazino does not come down clearly in favour of either side, although the tone of the essay creates a fundamental sympathy for the childlike mode of perception. As such, he does not assess the sensory capacities of children to be deficient, either in terms of attention or linguistic-intellectual capacity. Instead, to go one step further, it is exactly this ability not to have to understand viewed images that constitutes the deciding perceptual advantage of children.

Children, I would like to argue, find access to avant-garde and experimental films easier than many adults, because their perceptual mode coincides with the aesthetic concepts of these films. This is particularly true for films that abstract from the images of the world or that work with fragmented, non-linear image formations, and therefore disturb the hermeneutic cognitive process from the outset. As the following quotations from Peter Kubelka and Stan Brakhage make clear, avant-garde and experimental films also work against the common cognition models criticized by Genazino - either the hermeneutic anticipation of or access to knowledge, or the culturally acquired, ingrained pattern of perception:

It's a complete lie that people don't understand. It's just because people have entrenched expectations. For all of my films it was the case that at the premiere, the kids that whoever had brought along with them liked it straight away. The kids have always, always liked it. ... Back then, when the Schwechater film was shown, that was '58, it was said ... there is no single frame, you don't see it! Single frame, you don't see it, because it's too fast! And then the film, it's made up of nothing but single frames ... and people really sat there, seriously claiming that they didn't see anything, because they knew that you can't see a single frame. (Peter Kubelka;' translated by Stefanie Schlüter)

Imagine an eye unruled by man-made laws of perspective, an eye unprejudiced by compositional logic, an eye which does not respond to the name of everything but which must know each object encountered in life through an adventure of perception. How many colours are there in a field of grass to the crawling baby unaware of 'Green'? How many rainbows can 
light create for the untutored eye? How aware of variations in heat waves can that eye be? Imagine a world alive with incomprehensible objects and shimmering with an endless variety of movement and innumerable gradations of colour. Imagine a world before the 'beginning was the word'. ... Once vision may have been given - that which seems inherent in the infant's eye, an eye which reflects the loss of innocence more eloquently than any other human feature, an eye which soon learns to classify sights, an eye which mirrors the movement of the individual toward death by its increasing inability to see. (Brakhage, 2001: 12)

As in Genazino's model, two different perceptual modes stand in opposition to each other in these quotations from avant-garde film-makers. If the three positions are combined, the childlike perceptual mode can be characterized by its fundamental openness and flexibility, as children neither receive their impressions through the filter of standardized codes of perception nor translate these into linguistically coded units of meaning. Rather, children still have a sense that it is impossible to completely acquire the images of the world and of film rationally, and so the body becomes a sensory resonance chamber for aesthetic experience. In the cinema, this can be seen, for example, when children watching a film by Len Lye suddenly begin to dance in their seats.

The other mode, assigned to the adult world, is always trying to systematize the perceptual impressions linguistically, to add fragments together to create (firm) units of meaning, and to assume a decipherable meaning for the perceived phenomenon. This mode of experience insists on stable rationale, and does so at the expense of its sensuality. Thus, as Kubelka says, an aesthetic experience can prove futile if 'acquired knowledge' is not confirmed by the images.

My goal here is not to play off the two modes of perception against each other. Instead, the positions help us understand why avant-garde and experimental films have not found a place in film education in schools. Furthermore, these positions seem interesting to me because they allow the formulated perception modes to relate directly to the aesthetics of film. If the aesthetic concepts of an avant-garde and experimental film-maker orient themselves around the ideal of 'childlike perception', as is suggested in the quotation from Brakhage (2001), this is not based on the naive idea that one could regress a step backwards to an earlier stage of cognition. The recourse to the childlike perception mode rather serves the film-maker as a matrix for the development of aesthetic strategies, which in turn should allow the viewer access to other modes of perception. Indeed, many films within the tradition of avant-garde and experimental film free their viewers from the compulsion to interpret by targeting the cinematic aspect of film as much as the senses. Examples might include animated films by Hans Richter, Marie Menken or Ute Aurand, and hand-painted or scratch films by Len Lye and Stan Brakhage, which children access easily, whereas their teachers must be shown how to access them. ${ }^{9}$ School as a place of overwhelmingly linguistically led teaching, as a place of meaningful production and the passing on of knowledge, has difficulty engaging with open-ended aesthetic processes, particularly also due to the fact that it is supposed to impart a stable world-view to children and young people.

As a school can hardly draw on experience with these cinematic forms of its own accord, it seems to be necessary to bring external facilitators on board. And because purely linguistic education is always pushed to its limits when dealing with images, film-makers should be included so that children can also acquire aesthetic knowledge in practice. In the following, I will present a practical example that puts forward a haptic approach to avant-garde cinema. 


\section{Hands on: From the hand to the head and back}

Cinema is based on the materiality of films, but as viewers we almost never come into contact with the material. In multiple practical workshops on avant-garde and experimental film, I addressed this lack together with the film-makers Ute Aurand and Robert Beavers and the sound artist Dirk Schaefer, by devoting a large part of the workshop to cinematic practice, in which the 'grasping' of the materials was central: the children made films without cameras, making it therefore literally a sensory cognitive process that was initiated by touching, handling and physical contact with the celluloid (see Figure 1). ${ }^{10}$
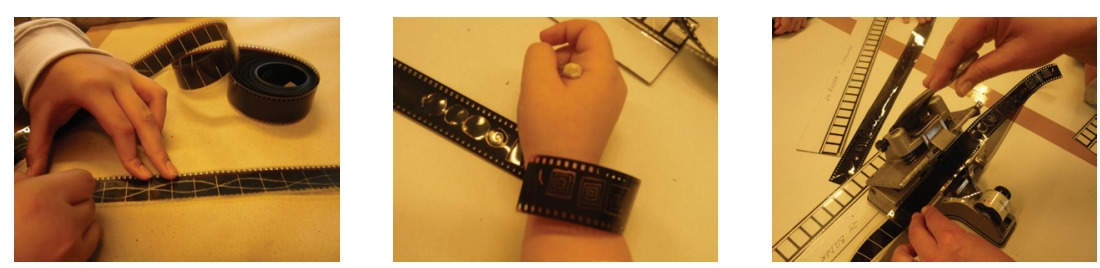

Credit: Stefanie Schlüter

Figure 1: Photographs from the film workshops

The opportunities to experience and to learn that are offered to children through the haptic editing of $35 \mathrm{~mm}$ film seem to me to be essential for the film education process. Without this, children, the majority of whom grow up with digital media, can hardly develop a concrete idea of what a moving picture is. For example, to the question of what they understood by 'animated film', children answered that it was a film that was made either at or by a computer. But what and where is this image allegedly created by the computer, and how does it move? The children's answer does generate follow-up questions, but these questions no longer target something concrete and visible, but rather invisible computer operations. Increasing digitization has therefore not made analogue film materials obsolete in education. On the contrary, the current situation demands concrete objects of study, which is why I bring children, young people and even adults into contact with film material as often as possible. I regularly roll out film copies that are no longer in use in cinemas, and we stretch the filmstrips out in the space in such a way that everyone present can take the film in their hands, study the frames on the strip, and get an idea of the successive sequence of the individual frames.
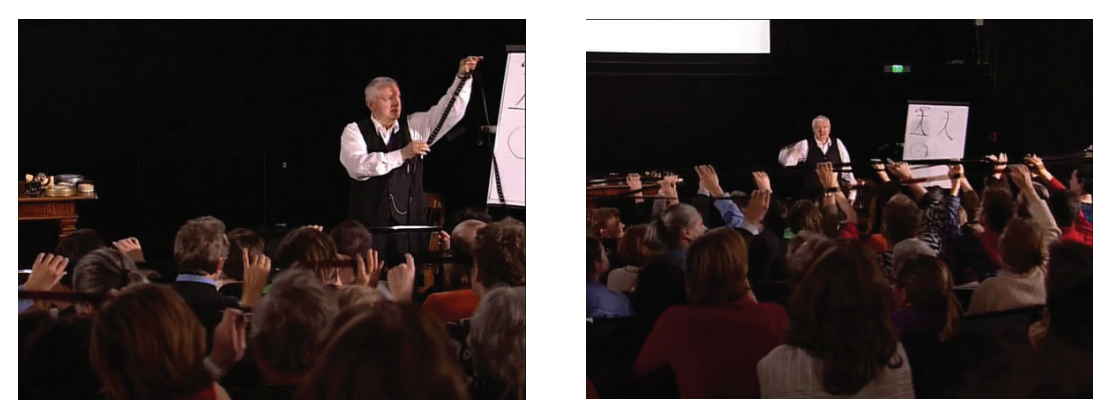

Figure 2: Stills from the film Film als Ereignis, Film als Sprache, Denken als Film ['Film as event, film as language, thinking as film'], a lecture performance on DVD by Peter Kubelka, which took place on 10 November 2002 in the Austrian Film Museum (Vienna) 
Artistic practices, such as that shown here in a sort of Expanded Cinema initiative (see Figure 2), can also provide demonstrative models for education, because they have an underlying educative impulse: in the example cited, this impulse lies in deictic strategies that are intended to serve the widening of opportunities for cinematic experience.

In the process of haptic editing of celluloid, the hands are assigned the mediating role, as they make up the somatic interface between the objects in the world and the senses. They are therefore not purely tools carrying out the tasks of a reasoning brain, but can be understood as 'intelligent instruments of cognition', 'which do the groundwork for the sensory organs and the brain, so that these can understand themselves and the world' (Huber, 2007: 11). In this way, drawing, for example, is a complex process of translation, 'which takes place in a state of constant feedback between the controlling visual system, the sensorimotor brain and the acting hand in an environment' (ibid.: 12).

Because the children in our workshops were not given any thematic guidelines, they approached the material in completely different ways. Some started by treating the material in a spontaneous, impulsive or even joyfully destructive way. Ultimately, one has to start by developing a feeling for the material and one's own motor skills in dialogue with the material. Some of the chance products that arose from such spontaneous actions by the children are among the best results from the workshop.
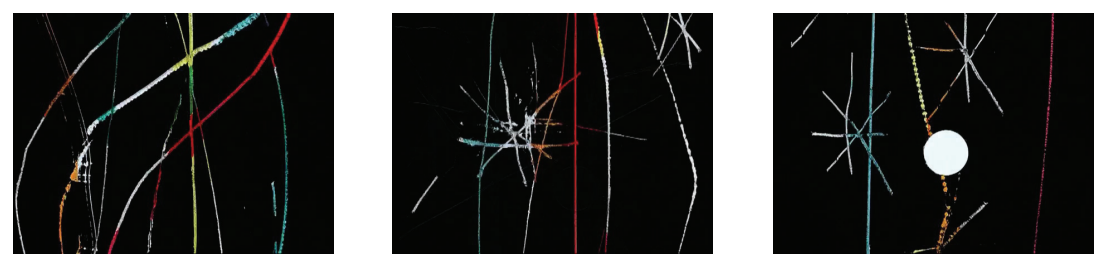

Figure 3: Stills from the children's film, Kratzig I ['Scratchy I'] (2010)

It could, however, be observed that many children gradually started to plan their work: they developed some partially abstract and partially concrete image ideas for animations (see Figure 3). From their ways of working it was clear that a mental process had been initiated, with the hand as its starting point. Painting on a strip of film, in contrast to drawing a picture, involves actively thinking about how to structure fixed forms on the filmstrip, which will then be brought into motion by the projector. ${ }^{11}$ The painting or the scratching of a successive series of images, the conversion of single images into temporal units of seconds and minutes - these are stages of abstraction that are not easily understandable for children from the outset, but that become gradually accessible with practical experience. In this way, one girl, clearly inspired by Hans Richter's film Rythmus 21 (1921), made white rectangles against a black background wander through the image in different directions, in the course of which the rectangles also got successively bigger and smaller. As is also reflected in the workshop report of one student, in film practice, sensory-aesthetic experiences interlace with acquired knowledge, for example about the temporality of film:

When you paint on to a filmstrip the colours glow so prettily, and on the screen [at the editing table] it looks like a colourful fire. We scratched on the film with the scratching tools. We could scratch out faces and little people and patterns. If you wanted to scratch or paint for just one second, you had to paint (scratch) 24 pictures. You could also make the film [at the 
editing table] in a time lapse or in slow motion. If you scratch or paint you don't need a camera, but later, when you see your scratch and painted films ... on the big projection screen you just can't believe that you made this film just with everyday things (pens, needles). Everything flashes on the projection screen and the patterns whoosh ... past. ${ }^{12}$

What amazed us in all of the workshops was the strong affective relationship that everyone involved had with the film material. The perseverance some children showed was comparable to that of marathon runners. While painting a filmstrip, one boy summed it up as follows: 'I could do this for 24 hours a day!'

\section{On the analytic treatment of avant-garde cinema}

\section{Two styles of teaching}

When I think back to my time at school and as a student - and in principle all teaching and learning situations - I remember two types of teacher. There were those who were able to get to the heart of a difficult problem with astonishing clarity. They had a talent for building linguistic bridges to the subject matter that was being taught (a poem, a painting, a historical source or a mathematical problem). You followed what they said, and were impressed by its transparency.

And there were other teachers who made the opaque and the erratic fascinating. In this method of teaching - if it is one - it was not a piece of knowledge about a thing that was conveyed. What was conveyed was rather that the topic was interesting. Sometimes it was unclear what exactly made it interesting, or how the topic worked, but exactly this lack of clarity was an incentive to learn more about it. A gap, not a bridge, appeared between teacher and student. But on the other side of the gap was someone standing in front of the class whose excitement was palpable even from a distance. ${ }^{13}$

The first, surely textbook, model can be characterized as a direct, explicit, discursive, outwardly directed teaching method. The second, in contrast to this, functions indirectly, implicitly, almost hermetically, because what is crucial occurs between the teacher and the topic, and is not clearly directed towards the students. It is more like watching someone research than watching someone teach. My knowledge of didactics is not all that broad, so I am unable to guess whether the second type would appear in a handbook on teaching styles - and if it would, whether it would be more likely to serve as an example or as a cautionary tale. But I would claim that the experimental films that I want to introduce here as 'films that teach about film' are modelled after this type. In them, you see an enquiring, intensive examination of the principles, materials and particularities of the medium of film. However, this confrontation between film-maker and material is not explicitly stated, but rather performed. Or, to phrase it differently: something is shown, not explained.

But what do these films show? They show first and foremost something that the primary school pupils experienced on the very first day of the experimental film workshops described above, when viewing historical cartoons and animated films: 'cinema' and 'film' cover far more than stories that unroll on a screen. A considerable proportion of what we call experimental or avant-garde film has no actors, does not tell a story, and moves in a sphere far away from mise en scène and happy endings. Indeed, in many cases - the workshops with the children and young people also show this - these films do not even use a camera, because footage is edited directly by hand, with pens or with other tools. The broadening of the spectrum of what film and 
cinema can be is therefore the first and perhaps most important lesson, and it can be considered a historical lesson today, as certain types of film - 8mm, 16mm - are becoming extinct and turning into historical artefacts. ${ }^{14}$

It is key for this type of education that it is based on the power of images and not of words: the instrument of education - as well as its subject - is film, and this simple statement implies a whole series of complicated questions: What does an education that is based on images, not words, look like? What does it mean that the experimental films in the title of our text are not (or not only) objects, but above all the subject and agent of teaching itself? To begin with a very simple observation, there is no commentating text in the vast majority of these films; the educative techniques used are operations such as montage, new sound, or the reworking of material. In short: the techniques of film itself.

This is worth emphasizing because we are used to every form of education taking place through the medium of language. Mathematical equations, aesthetic forms, grammatical structures - seemingly everything can be 'converted' into words, so that language is almost the medium of education per se. But there are strong arguments that this notion should be questioned and confronted with the claim that knowledge of images surely has its own irreducible quality. If everything that happens in images could be converted into language without a trace and without any loss, why do we need images at all? With the keywords pictorial turn and iconic turn, this idea of the autonomy of images has gained academic momentum since the 1990s, and has exacted genuine theories of the image (see Mitchell, 1994; already discussed in Maar and Burda, 2004).

The idea of the autonomy of images touches upon numerous questions that have occupied, in particular, the modernist view of art almost obsessively. The conviction that was most vehemently represented by the American art critic Clement Greenberg could be formulated as follows: painting is not about religious motives, landscapes, portraits of rulers or still life. Painting is about flatness (while sculpture is about space). It is about colour and canvas and brush: its material is also its subject. 'It quickly emerged', Greenberg writes in 1960, 'that the unique and proper area of competence of each art coincided with all that was unique in the nature of its medium' (Greenberg, 1993: 86) - an assessment that also leads him to a problematic idea of medial purity. ${ }^{15}$ Between the Impressionists, Kazimir Malevich and Yves Klein, this intuition has been researched, studied and explored in painting in ever-new practical approaches since the late nineteenth century. In film history, it broke ground particularly in the area of experimental film in different approaches and conjunctures. The term 'absolute film', which was used in the 1920s to characterize a whole movement, is driving directly at this. If the term is taken literally, it means that the medium of film should be used in its own right, removed from other reference points used by film to orient itself, not as the realization of a book by another means, and not as moving paintings. Birgit Hein and Wulf Herzogenrath concentrated on this thought when they curated their influential exhibition with the title 'Film as Film' in 1977: precisely not 'Film as Art', the trend-setting title of Rudolf Arnheim's 1932 book (Arnheim, 1957), but as film - under its own conditions, with its own devices and, one could add, with its own, filmic, forms of teaching (see Hein and Herzogenrath, 1978). In the following, I would like to present three films that form part of this tradition in different ways, and that raise and deal with matters of education completely differently. 


\section{Motion and stillness (Pasadena Freeway Stills)}

Pasadena Freeway Stills was directed by Gary Beydler in 1974. The title already describes exactly what can be seen in the six minutes of the film. Beydler shows a multitude of stills, or, more precisely, frame enlargements from a film copy, which he holds up to a sheet of glass one after another. The photographs face the camera and are fitted into a restricted frame in such a way that they always appear in the same place. They show phases of an everyday motion sequence: a car journey on the freeway between Los Angeles and Pasadena. Initially, the images are shown one after another at intervals, and are therefore separated from each other discretely (see Figure 4).
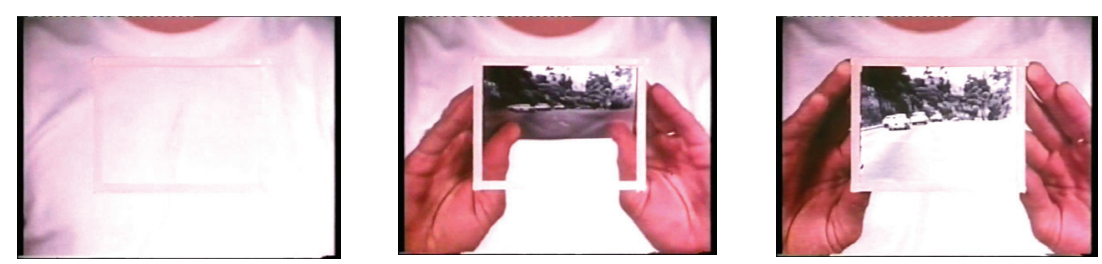

Figure 4: Stills from Pasadena Freeway Stills (1974)

In the background of the picture, Beydler's T-shirt and hands can be seen in jump cuts; in the photographs, the cars on the motorway jerk forward erratically. Then the frequency increases. The image jumps in the background accelerate, and at the same time the motion of the image within the photograph becomes more fluid. By the middle of the film, the image flows continuously. At this point, we probably see about 24 photographs per second: the cinematic motion of the source material, the $16 \mathrm{~mm}$ film from which the stills were made, is reconstructed as a sequence of 24 stills per second. After this peak, during which the photographs have transformed themselves into film, while the filmed background is clearly recognizable as the result of individual images, the process reverses itself. It begins to slow down, and the 'film' becomes a sequence of individual images again. ${ }^{16}$

What happens in this short lesson, and to what extent does it teach about film? You could say that Beydler's film analytically isolates a core element that characterizes 'film as film': the principle of motion. The photographs, the basic building blocks of film, are added together to create a film, before they fragment back into individual pictures. One of the many origins of cinema - many would say the central origin - is not just addressed, but also performed in this surprising and elegant gesture. Pasadena Freeway Stills turns inside out something that characterizes film, in the same way that you would turn over a piece of clothing to be able to better recognize its stitches and underlying design. I am sure that it would be rewarding to watch this film with children, and that the related phenomena and picture media, for example the flip-book, would occur to them almost automatically. It would also be easy to move the discussion to the different forms of sequential photography, such as that invented by Eadweard Muybridge and Étienne-Jules Marey in the 1880s, within the framework of their studies of motion.

Without the filmstrip in Beydler's film being materially visible, its inherent principle - seriality, a sequence of frames - becomes the crucial conceptual idea. The film is like a blueprint of cinematography; in a purely deictic form it asks the complicated question of motion, which has occupied theories of time, and with that theories of film, repeatedly, from Zeno of Elea to Henri Bergson, and Gilles Deleuze to Tom Gunning. ${ }^{17}$ 
In the 1960s and 1970s, many film-makers followed the impulse to explore individual types and core elements of the medium of film and of cinema. Beydler's film therefore typifies a number of works. The relevant question is one of 'medium specificity', or rather the question of what the cinematic medium specifically is, and what sets it apart from other media. One could list various films that, as in a laboratory, analytically isolate individual principles of film and cinema, just as Beydler does for the constitutive relationship between stillness and motion. Some films by Morgan Fisher, which I will return to later, are particularly exemplary in doing this: Production Stills (1970), in the duration of a roll of $16 \mathrm{~mm}$ film, shows how a series of Polaroids are taken and shown, in which the production process of the film we are watching is depicted in extracts and at first enigmatically. And in Projection Instructions (1976), also by Morgan Fisher, the usually invisible projectionist becomes the protagonist, when before our eyes they have to follow all imaginable instructions: make the picture sharp or blurry, move it upwards or downwards, to the left or the right, turn the sound up or down. In this, Projection Instructions teaches more about cinema than about film: it does not make any sense outside cinematic practice. ${ }^{18}$

But individual image frames, motion and projection are not the only things that belong to cinema: there is also the film material, such as the children in the workshops got to know as blank film or found film material that they could scratch, paint, perforate or put through the sewing machine. Another important branch of the history of experimental film is dedicated to exactly this aspect. It has become known under the term 'found footage', although some of the film-makers do not necessarily simply happen across the material they work with, but search for it systematically and make it accessible in archives. ${ }^{19}$ Having used Beydler's film to draw attention to the historicity of the principle of motion, I will now discuss the topic of the historicity of images.

\section{Material and narrative (L'Arrivée)}

Since the 1960s at the latest, there has been lively interaction between early cinema and the avant-garde (see Blümlinger, 2004). One of the first films to go down in cinematic history shows a train driving into the picture, and countless film-makers and theoreticians have returned to this elementary sensation of motion as though to a traumatic primal scene (see Kirby, 1997).
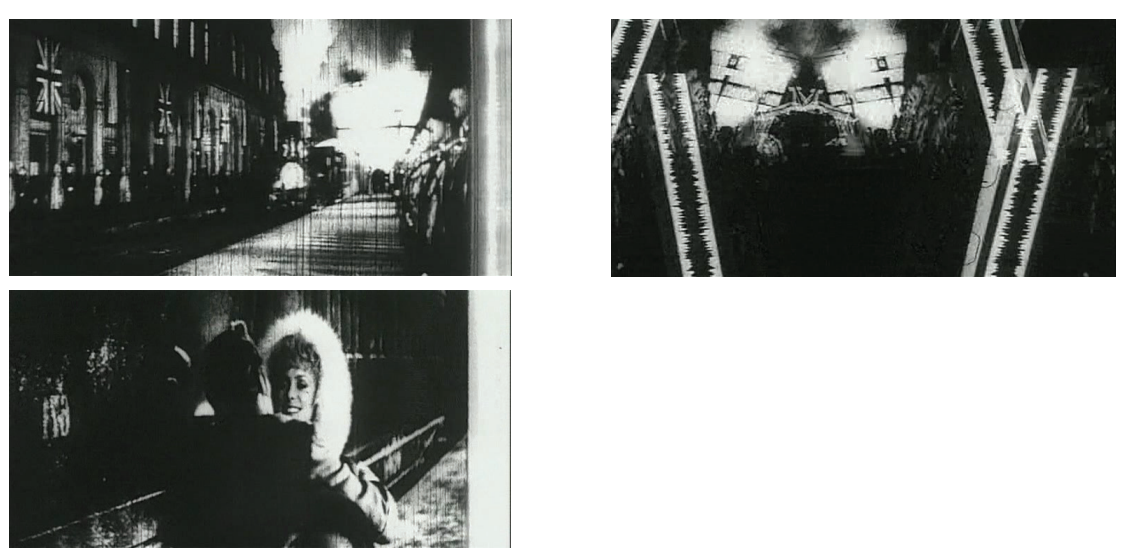

Figure 5: Stills from L'Arrivée (1997/8)

The train that enters the picture in Peter Tscherkassky's L'Arrivée (1997/8) (see Figure 5) comes from a film from 1968, but refers explicitly to that first train by the Lumière 
brothers. That said, the shot, which Tscherkassky edits, attacks, copies, reflects and renders strange over and over almost to the extent of unrecognizability, was originally not directly reminiscent of the Lumière brothers' train's entrance into La Ciotat station. Whereas that train comes from the back right to the front left towards the viewer in a beautifully framed diagonal, in Mayerling (1968), from whose trailer Tscherkassky made his film, the train arrives in Vienna's main station from the opposite direction.

Tscherkassky has emphasized that the literal handling, or touching, of the material was essential for the making of the film:

The source material was an ancient trailer; I didn't have the complete film, just this three-minute compilation. It only became apparent that this shot looked like the Lumière brothers' approaching train when I had the filmstrip in my hand and turned it over and looked at it back-to-front. That way the train was then coming from right to left into the picture, no longer from left to right. But that lies in the fact that you can actually do that with a filmstrip..$^{20}$

In contrast to Beydler's sober and regularly constructed film, in the course of the compressed and condensed two minutes of L'Arrivée, three arrivals can be clearly differentiated: at first we see the arrival of the train, then the arrival (or rather the breaking in) of the material and then, third, the arrival of the woman - Catherine Deneuve - who gets off the train and is greeted with a kiss on the platform. If the film is understood as a lesson in film history, the beginning and end follow two clearly different narrative styles. The violent middle section, in which soundtrack and film perforations - in short, the paratexts of the film material - push inwards, orchestrates the transition point between the two.

The first shot, in which the train, like the film image, moves slowly to the centre of the screen, is a kind of remake of the Lumière brothers' film. Using Tom Gunning's (1990) influential term, it could be said that the 'cinema of attractions' is at work here. In the early days of cinema, until about 1907, the period that Gunning had in mind, no montage or narrative effort was required to captivate the attention of the audience. There was also no need for protagonists or actors: the motion of the train alone was enough of an attraction, and at the start of film history, such motion created excited astonishment in viewers, which - contrary to the legend of the frightened audience was in no way naive or ignorant.

In contrast to the Lumière brothers' train, and with countless other trains in early cinema, the train in L'Arrivée does not arrive unimpeded in the station. The film material allows it to literally jump out of its tracks. Perhaps it would be more precise to say that the tracks, that is film perforations, become independent and step inside the field of the image, and, as such, inside the field of the narrative. The frame becomes the image, while the image is pushed out of the frame. This does not just entail an empowerment of the material over the 'content'. In a nutshell, a movement from the 'cinema of attractions' to narrative cinema takes place, as it was initiated from 1908 by directors such as D.W. Griffith. Tscherkassky himself gets to the heart of the allegorical nature of his film when he writes: 'Reduced to two minutes L'Arrivée gives a brief, but exact summary of what cinematography (after its arrival with Lumiéres' train) has made into an enduring presence of our visual environment: violence, emotions. ${ }^{21}$

In L'Arrivée, the view Tscherkassky takes of the superpower that is emotional narrative is ambivalent. It is true that it does not require a huge effort to view his film as a criticism of Hollywood cinema, which has always been a central motivation for the avant-garde. At the same time, however, L'Arrivée participates in the kiss and the 
emotional ending, in Catherine Deneuve's appearance and the punchline that this gives the film. Whether rejection or fascinated appropriation, in this obsessive editing of the video and soundtrack, affects are at play that are subdued in the simple elegance of Gary Beydler's film or overall in the modernist tradition.

This points to a difference that partly explains the prominence of found footage work, especially since the 1980s. The Greenbergian construction of modernism in particular raised the objection that the issue of medium and artistic specificity was inadmissibly made into an absolute, and that artwork was separated from its historical and social contexts under the tagline of 'autonomy'. Moreover, Greenberg's (1993) puristic and elitist 'pure mediality' tended to be restricted to phenomena of high culture. In the light of this problem, found footage film gains special significance because it does not set aside the question of medium specificity, but rather asks it in a completely different way, working with existing and often seemingly insignificant material. In Hollis Frampton's (2009: 136) influential text 'For a metahistory of film: Commonplace notes and hypotheses', he writes: 'There is no evidence in the structural logic of the filmstrip that distinguishes "footage" from a "finished" work. Thus, any piece of film may be regarded as "footage", for use in any imaginable way to construct or reconstruct a new work.'

Every piece of film, whether exposed or unexposed, is potential source material for one's own film work: in this premise, found footage film and initially its representatives in the US avant-garde have belatedly found their founding principle. Film-makers such as Ken Jacobs or Ernie Gehr, and later Austrian film-makers - surely by way of Peter Kubelka's initiatives, bringing numerous avant-garde film-makers from New York to Vienna as director of the Austrian Film Museum - adopted the reworking and appropriation of cinema. In the cases of Peter Tscherkassky, Martin Arnold and Gustav Deutsch, working with existing materials certainly has its own, sometimes completely different implications for questions of education. In his Cineseizure trilogy (1989, 1993 and 1998), Martin Arnold refers to narrative mechanisms in Hollywood cinema, whose latent structures he uncovers by displacing short segments into compulsive stuttering of the images and sounds until they almost speak against themselves. Gustav Deutsch, in contrast, works in a phenomenological way with inventories of specific archives in the now three compilations of his Film Ist. ['Film is.'] series (1998, 2002 and 2009). He often uses functional films or scientific films, and therefore once again another branch of cinema, which is often labelled as 'ephemeral'. ${ }^{22}$

Working with found footage offered a way forward from modernist reductions in the context of so-called 'structural film'. Malevich's Black Square led painting to an end or zero position, but people continued to paint after Malevich. In a similar way, Peter Kubelka or Tony Conrad led cinematography back to white and black image frames, but people wanted to be able to continue making films after them. The reconditioning and reworking, the appropriation and expropriation of existing material allowed this: a critical and referential approach made way for a return to the subjects and narratives. They could be told again in the mode of analysis, often also in an iconoclastic spirit of destruction. Helmut Färber made the observation that there are two motives for dissecting a bird: either to eat it, or to find out how to fly. In avant-garde film, both impulses, I believe, can be found: the exploratory and dissecting impulse, and the aggressive and cannibalistic one. A film such as L'Arrivée can also show that in the editing of the material, emotion and temperature pour into the comparatively cool dissecting practices of modernism in a new way. 


\section{Format and emotion (Standard Gauge)}

The third and final film that I want to present as a film that teaches about film is by Morgan Fisher. I can be brief in doing so, as Fisher himself has written so enlighteningly about his film that there is little left for me to say. The film is called Standard Gauge (1984) and takes us from Tscherkassky's complex densifications and layers back to a perfectly simple design (see Figure 6).
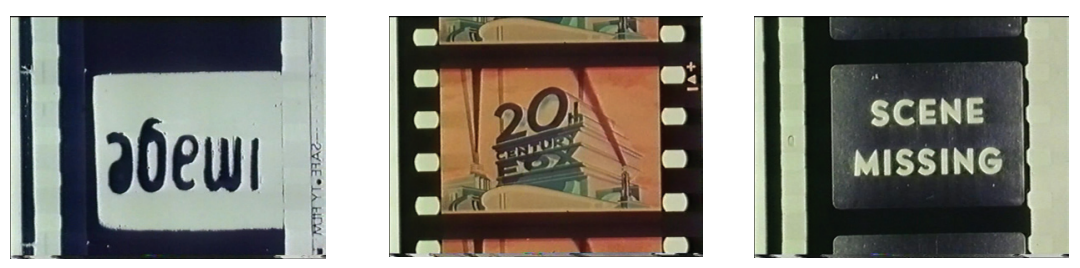

Figure 6: Stills from Standard Gauge (1984)

Standard Gauge is made up of the following three components: a light table, about thirty filmstrips of different lengths, and the commentating voice of Morgan Fisher. From the beginning, the title points to the crucual film-historical format specification, which is outlined in a long rolling text. As early as 1894, Thomas Edison and his inventor William K. Dickson determined the format of $35 \mathrm{~mm}$ for the kinetoscope, a display unit for roll film that could only be used by one individual person because the pictures were not projected. When they encountered Dickson's invention, the Lumière brothers took on the format for their cinematographs. This marked the triumph of $35 \mathrm{~mm}$ film, which became known as the standard gauge.

The central idea of Fisher's film lies simply in the fact that although it shows exclusively $35 \mathrm{~mm}$ filmstrips, his film itself is made on $16 \mathrm{~mm}$ film, whose maximum roll length also prescribes the length of the film. Fisher described the structure and concept of his film as follows:

Although the film is one continuous shot, each piece of film fills the frame and so inflects the embracing shot, creating within it the affect of a succession of shots. So the film combines two conventions usually held to be mutually exclusive, or even antagonistic: editing - the construction of a film through montage - and the long take, the impassive recording of a scene that has been arranged with some purpose in mind. Just as Standard Gauge amalgamates the two great conventions of film composition, it also brings together narrative and non-narrative filmmaking. By examining the shards of the industry frame by frame, it discovers some of the means and themes of experimental film living, so to speak, in Hollywood. And at the same time, the film engulfs and usurps the material of the commercial motion picture industry, turning it into its subject. Thus Standard Gauge proposes a kind of mutuality or interdependence between two kinds of filmmaking that by conventional standards are thought to be divided by an unbridgeable chasm. By means of a mutual interrogation between $35 \mathrm{~mm}$, the gauge of the industry, and $16 \mathrm{~mm}$, the gauge of the independent and amateur, Standard Gauge proposes to unify film of every kind. ${ }^{23}$

Standard Gauge is therefore both narrative and experimental film, $35 \mathrm{~mm}$ and $16 \mathrm{~mm}$ film, montage and sequence shot. 


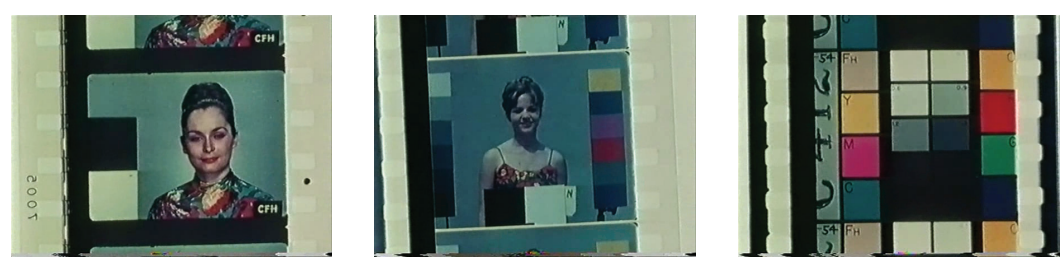

Figure 7: Stills from Standard Gauge (1984)

In a different manner to Tscherkassky, the section on the 'China-girl' likewise puts what is displaced and suppressed in film centre stage (see Figure 7). ${ }^{24}$ It shows us a series of test shots in which women wearing colourful clothes pose for the camera, so that the colour identification of the film, in particular the difficult skin tones, can be dealt with in the film laboratory. The women serve only the calibration of the machine and remain invisible, like lighting technicians, cable bearers or production drivers, albeit with the categorical difference that they appear on the film as 'any piece of footage' in Frampton's (2009) sense, in the same way as actors also appear on film. By observing them in this way, Fisher sides with the hidden film workers, who remain invisible because industrial cinema tends to conceal its foundations or banish them to the offstage area of the paratext. However, he values the images - and all other film snippets as well not least through their aesthetic quality, which is reminiscent of Mondrian's paintings. ${ }^{25}$

In the context of questions of teaching, I would like to emphasize the highly subjective tone in which Fisher tells of his encounters with pieces of film. The structure is built on autobiographical moments: it deals with film that he was confronted with as a cutter, or in other functions within the film industry; with film rolls that he saved from studio bins; with enigmatic images from nameless films; and again and again, with pieces of film leader or other film paratexts, which have always been of interest for avant-garde cinema because they negotiate the relationship between centre and periphery. In a casual way, a sort of history lesson is created, in which matters of film production and of film material are touched on, as well as such colour and sound film processes that can be read from the footage. The affective connection to these pieces is central to this. In the confrontation between teaching models with which I began, Fisher therefore participates in both forms: unlike Beydler and Tscherkassky, there is a commentating text here, which is directed to the viewer in a discursive and explanatory way. However, the interesting thing here plays out between Fisher and the material, and the viewer is witness to this confrontation. Consequently, the film ends with the laconic words: 'Here are some pieces of film that I think are interesting to look at', a deictic gesture followed by five minutes of film segments without any comment.

\section{Conclusion}

In conclusion, I give a few thoughts on the three points of departure for my perusal of film. In the discussion of Gary Beydler's Pasadena Freeway Stills, I began by focusing on the relationship between stillness and motion as one of the core issues of the cinematic process. 'The relationship between cinema and still photography', Hollis Frampton (2009: 134) wrote, 'is supposed to present a vexed question. Received wisdom on the subject is of the chicken/egg-variety: cinema somehow "accelerates" still photographs into motion.' Furthermore, Beydler's film makes reference to a central concern of modernist projects. Beydler shares an interest in researching the medium 'film' with many others, for example film and media scholars. At the moment 
in which this research itself becomes a film, a film that teaches about film emerges. The question of medium specificity is therefore both suspended and pursued the same time in found footage film. The puristic impulse to reduce content as far as possible so as to concentrate on medium is suspended. Instead, the historicity not just of the medium, but also of its narratives, is brought to the foreground through confrontation with concrete material; the issue of technique is raised alongside that of historicity.

Morgan Fisher's film can also be understood as a history lesson, but it brings the autobiographical experiences of the teacher into play quite explicitly. Teaching practice, according to my understanding of Standard Gauge, is always a question of the emotion and the fascination that is provoked by the material. The hands that scratch and paint the celluloid in the children and young people's workshops are prominently at work in all three cases. Before the arrival of the computer and the dominance of digital image editing, the 'handmade' is a category that is much more central in experimental film than in industrial cinema, where the individual handgrip is lost in a chain of operations and can only be observed with difficulty. We see Gary Beydler's hands; we ask ourselves which procedures Peter Tscherkassky submitted the film to with his hands, in order to create a tempest of light and sound such as that in L'Arrivée; and we notice that the whole literal handling of filmstrips was one of the starting points for Standard Gauge.

I recently came across the hypothesis that all children are formalists: they are interested in motion, colour, forms and structures. The fixation on content, on which vast amounts of film education are based, perhaps comes only with puberty.

Before they are straightjacketed by semantics and meaning, children are media scholars.

\section{Notes}

1. In German, the title 'Teaching experimental film' allows two readings: it refers not only to working with experimental film and children and young people, but also to the educational character of the films themselves. The following text deals with the complementary experience with avantgarde cinema and the crossovers between practical and analytical work. The first part was written by Stefanie Schlüter, the second by Volker Pantenburg.

2. The film education boom of recent years clearly shows how films with commercial distributors fall largely unfiltered into education channels: 'film education' - at least in Germany - was and is still strongly connected with marketing and commercial exploitation.

3. As such, the existence of avant-garde and experimental film is not shown in school books or in other educational media, or in film journals for teaching, the publication of which has increased exponentially in recent years. An exception in Germany is the school book Grundkurs Film (see Klant and Spielmann, 2008).

4. Experimental films play no role in the aesthetic educational approaches that are currently most influential, for example the French models, in particular those by Alain Bergala.

5. In the independent research project Kunst der Vermittlung: Aus den Archiven des Filmvermittelnden Films ['Art of education: From the archives of films which teach about film'], we - together with Michael Baute, Stefan Pethke and Erik Stein - researched the potential of avant-garde and experimental films to teach about film itself in multiple interviews with filmmakers and texts on their films (www.kunst-der-vermittlung.de). Christine Rüffert (2009) uses the term 'films which teach about film' ['filmvermittelnde Filme'] in one of the few texts regarding the teaching of avant-garde and experimental films published so far.

6. A good example for the shaping of an artist through his perceptual environment is offered by Len Lye: as a child he lived in a lighthouse for a few years, which is the origin of his lifelong love of moving light (see Kothenschulte, 2009).

7. Peter Kubelka, cited from a television programme in the Österreichischer Rundfunk [The Austrian Broadcasting Corporation] series Apropos Film (broadcast: 13 October 1970). In this programme, Kubelka, together with Jonas Mekas, presents the newly opened Invisible Cinema in New York; he describes this as the fulfilment of a 'childhood dream'. 
8. Stan Brakhage has dealt intensively with themes such as 'childhood, primal sight, the beginning of consciousness, and the phenomenological discovery of the world' (Ganguly, 1994: 18).

9. In numerous cinema events with children, I have been able to observe how quickly they establish a direct connection to abstract, experimental films, and how they react almost immediately to these films. With the same films, I received mostly reserved, hesitant reactions at further education events for teachers.

10. This was a series of three five-day workshops, supported by Arsenal - Institut für Film und Videokunst [Institute for Film and Video Art], Berlin, as institutional partner. In the first two workshops, two fifth-grade classes from Hunsrück Primary School in Berlin-Kreuzberg, under the artistic direction of Ute Aurand and Robert Beavers, applied themselves to the work pictured: they created hand-painted and scratch $35 \mathrm{~mm}$ films and photographed abstract animations with a $16 \mathrm{~mm}$ Bolex camera. In the third workshop, a group of secondary school students from the Evangelical School in Berlin-Mitte set music to segments of children's films digitally, under the instruction of Dirk Schaefer. Each workshop began with a cinema screening in which experimental films from 1905 to the present were shown. The projects, supported by Berliner Projektfonds Kulturelle Bildung [Berlin Project Funds for Cultural Education], were carried out between January and March 2010.

11. Even just the tiny size of the film frame in comparison with a piece of paper, on which you can draw and paint freely, makes a big difference to conventional drawing processes. Working on a filmstrip forces reduction, and therefore abstraction. Working with scratching tools also requires much patience and force; it is not as easy to guide a screwdriver on celluloid as a pen or brush on paper.

12. Quoted from a workshop report by Anais (age 11), with additions by Stefanie Schlüter.

13. Both types of teaching correspond roughly to the teaching types that Roland Barthes (1989: 177) identifies in a text about his pupil Christian Metz: 'There are perhaps two ways of avoiding mastery (is this not the stake today of all teaching, of any intellectual "role"?): either to produce a perforated, elliptic, drifting and skidding discourse; or, conversely, to load knowledge with an excess of clarity.'

14. The vinyl record has shown that a cultural technique such as DJing is enough to prevent the disappearance of a medium.

15. For a different historicization of avant-garde film, backed by impurity rather than purity, see Jutz (2010). For a short rereading of Greenberg from a film-theoretical perspective see Doane (2010).

16. On the Light Cone website, which distributes the film, a description by Beydler on how he made the film is available: 'I had one of my graduate students drive the car, and I filmed $16 \mathrm{~mm}$ black and white negative driving through these four consecutive tunnels on the Pasadena freeway. I wound up doing about 1,400 paper prints from the individual frames in the negative. I mounted a piece of glass in my garage, with a square of tape marked out on it. I sat down behind the glass with a white T-shirt on and started shooting the stills. My wife Sarah shot the first part, and as the shots got shorter and shorter, I shot it myself using a bulb hooked up to the camera that I operated with my foot. I originally meant to shut it off and fade it out to end it, but while I was shooting, I decided instead to reverse the procedure, slowing the shots back down. I called Sarah back to shoot the last part. I always had the idea of sound, but I could never figure out what the heck kind of sound to have in this film' (https://lightcone.org/en/film-135-pasadena-freewaystills (accessed 10 October 2018)).

17. See Henri Bergson's text 'L'Evolution créatrice' [Creative Evolution] from 1907 (Bergson, 1922), Deleuze's $(1986,1989)$ Bergson comments in both cinema books, as well as Gunning (2007).

18. Production Stills: Morgan Fisher, USA 1970, 16mm, b/w, sound, $11 \mathrm{~min}$; Projection Instructions: Morgan Fisher, USA 1976, 16mm, b/w, optical sound, 4 min.

19. On found footage film, see Blümlinger (2009).

20. A physical cinema. Conversation with Peter Tscherkassky on the website for the project Kunst der Vermittlung [Art of Education] (www.kunst-der-vermittlung.de/dossiers/filmvermittelndeexperimentalfilme/gespraech-tscherkassky/ (accessed 3 October 2010)).

21. From Tscherkassky's comprehensive website (www.tscherkassky.at (accessed 3 October 2010)).

22. In the framework of the project Kunst der Vermittlung: Aus den Archiven des Filmvermittelnden Films [Art of Education: From the archives of films which teach about film], we spoke in detail with all three film-makers about their works as 'films which teach about film'. These conversations and many others (for example with Alain Bergala, Jean Douchet, Alexander Horwath) are documented on our website at www.kunst-der-vermittlung.de.

23. Morgan Fisher on Standard Gauge: from the website Constanze Ruhm: Fate of Alien Modes, exhibition in the Vienna Secession 2003 (http://constanzeruhm.net/portfolio/morgan-fisher. phtml (accessed 3 October 2010)).

24. The voice-over text is published in MacDonald (1995: 178-89). On China-girl, see Hüser (2002).

25. On Standard Gauge, see also Blümlinger (2009: 181-7). 


\section{Notes on the contributors}

Volker Pantenburg is Professor of Film Studies at the Free University of Berlin. He has published widely on essayistic film and video practices, experimental cinema and contemporary moving image installations. In 2015, he co-founded the Harun Farocki Institut, a non-profit organization designed as a platform for researching Farocki's visual and discursive practice and supporting new projects that engage with the past, present and future of image cultures.

Stefanie Schlüter works as a film educator at the Arsenal Institute for Film and Video Art in Berlin and other institutions. Between 2007 and 2009, she was part of the project Kunst der Vermittlung - Aus den Archiven des Filmvermittelnden Films. In the context of Living Archive: Archive Work as a Contemporary Artistic and Curatorial Practice at Arsenal, she initiated archive-based curatorial work with children. She is continuing this work within the framework of the project Archive außer sich.

\section{Filmography}

L'Arrivée (The Arrival, AT 1997/8, Peter Tscherkassky)

Cineseizure trilogy (AT 1989, 1993 and 1998, Martin Arnold)

Film Ist. series (Film Is., AT 1998, 2002 and 2009, Gustav Deutsch)

Mayerling (GB/FR 1968, Terence Young)

Pasadena Freeway Stills (US 1974, Gary Beydler)

Production Stills (US 1970, Morgan Fisher)

Projection Instructions (US 1976, Morgan Fisher)

Rythmus 21 (Rhythm 21, DE 1921, Hans Richter)

Schwechater (AT 1958, Peter Kubelka)

Standard Gauge (US 1984, Morgan Fisher)

\section{References}

Arnheim, R. (1957) Film as Art. Berkeley: University of California Press.

Barthes, R. (1989) 'To learn and to teach'. In Barthes, R. The Rustle of Language. Trans. Howard, R. Berkeley: University of California Press, 176-8.

Bergson, H. (1922) Creative Evolution. Trans. Mitchell, A. London: Macmillan.

Blümlinger, C. (2004) 'Lumière, der Zug und die Avant-garde'. In Hagener, M., Schmidt, J.N. and Wedel, M. (eds) Die Spur durch den Spiegel: Der Film in der Kultur der Moderne. Berlin: Bertz, 27-41.

Blümlinger, C. (2009) Kino aus zweiter Hand: Zur Ästhetik materieller Aneignung im Film und in der Medienkunst. Berlin: Vorwerk 8.

Brakhage, S. (2001) 'Metaphors on vision'. In McPherson, B.R. (ed.) Essential Brakhage: Selected writings on filmmaking by Stan Brakhage. New York: Documentext, 12-71.

Deleuze, G. (1986) Cinema 1: The Movement-Image. Trans. Tomlinson, H. and Habberjam, B. Minneapolis: University of Minnesota Press.

Deleuze, G. (1989) Cinema 2: The Time-Image. Trans. Tomlinson, H. and Galeta, R. Minneapolis: University of Minnesota Press.

Doane, M.A. (2010) 'Hat das Medium Gewicht?'. Zeitschrift für Medienwissenschaft, 2, 15-26.

Frampton, H. (2009) 'For a metahistory of film: Commonplace notes and hypotheses'. In Jenkins, B. (ed.) On the Camera Arts and Consecutive Matters: The writings of Hollis Frampton. Cambridge, MA: MIT Press, 131-9.

Ganguly, S. (1994) 'Stan Brakhage - The 60th birthday interview'. Film Culture, 78, 18-38.

Genazino, W. (2007) 'Der gedehnte Blick'. In Genazino, W. Der gedehnte Blick. München: Deutscher Taschenbuch Verlag, 38-61.

Greenberg, C. (1993) 'Modernist painting'. In Greenberg, C. The Collected Essays and Criticism: Volume 4: Modernism with a vengeance, 1957-1969. Ed. O'Brian, J. Chicago: University of Chicago Press, 85-93. 
Gunning, T. (2007) 'Moving away from the index: Cinema and the impression of reality'. Differences, $18(1), 29-52$.

Gunning, T. (1990) 'The cinema of attraction(s): Early film, its spectator and the avant-garde'. In Elsaesser, T. and Barker, A. (eds) Early Cinema: Space, frame, narrative. London: London: British Film Institute, 56-62.

Hein, B. and Herzogenrath, W. (eds) (1978) Film als Film: Vom Animationsfilm der zwanziger zum Filmenvironment der siebziger Jahre. Stuttgart: Hatje.

Huber, H.D. (2007) 'Die Intelligenz der Hände'. BÖKWE, 1, 10-15. Online. www.hgb-leipzig.de/ ARTNINE/huber/aufsaetze/intelligenz_der_haende.pdf (accessed 2 October 2010).

Hüser, R. (2002) 'Found Footage Vorspann'. In Liebrand, C. and Schneider, I. (eds) Medien in Medien. Köln: DuMont, 198-217.

Jutz, G. (2010) Cinéma brut: Eine alternative Genealogie der Filmavant-garde. Wien: Springer.

Kirby, L. (1997) Parallel Tracks: The railroad and silent cinema. Durham, NC: Duke University Press.

Klant, M. and Spielmann, R. (2008) Grundkurs Film 1: Kino, Fernsehen, Videokunst. Braunschweig: Schroedel.

Kothenschulte, D. (2009) Frei und Radikal: Len Lyes absolutes Kino an den Schnittstellen des Unvereinbaren (Avant-garde, Experiment und Underground 2). Köln: Strzelecki Books.

Maar, C. and Burda, H. (eds) (2004) Iconic Turn: Die neue Macht der Bilder. Köln: DuMont.

MacDonald, S. (ed.) (1995) Screen Writings: Scripts and texts by independent filmmakers. Berkeley: University of California Press.

Mitchell, W.J.T. (1994) Picture Theory: Essays on verbal and visual representation. Chicago: Chicago University Press.

Pantenburg, V. and Schlüter, S. (2011) 'Experimentalfilme vermitteln: Zum praktischen und analytischen Umgang mit dem Kino der Avant-garde'. In Hediger, V., Sommer, G. and Fahle, O. (eds) Orte filmischen Wissens: Filmkultur und Filmvermittlung unter digitalen Netzwerkbedingungen. Marburg: Schüren, 211-34.

Rüffert, C. (2009) 'Lichtspiele unter der Lupe: Filmvermittlung anhand von Experimentalfilmen'. In Henzler, B. and Pauleit, W. (eds) Filme sehen, Kino verstehen: Methoden der Filmvermittlung. Marburg: Schüren, 93-117. 